\title{
The longitudinal effects of children's temperament on maternal depression: A hierarchical linear modeling approach
}

\author{
Kim, Chul-Gyu' ${ }^{1)}$ (D) Choi, Mi-Young ${ }^{1)}$ (D) \\ 1) Professor, Chungbuk National University
}

\begin{abstract}
Purpose: This study aimed to identify the longitudinal effects of children's temperament on maternal depression. Methods: Data from a longitudinal cohort of the Panel Study of Korean Children (PSKC) from 2010 to 2012 were analyzed using hierarchical linear modeling. The survey included 1,721 mother-child dyads. The mothers reported on their children's temperament and on maternal depression. The children's temperament was measured by the Emotionality, Activity and Sociability-Temperament Survey for Children-Parental Ratings, while maternal depression was measured by the Kessler 6 Psychological Distress Scale. Results: The results showed that both children's temperament and maternal depression were relatively stable when the children were between the ages of 2 to 4 . The mean maternal depression scores were 11.83 in 2010, 11.88 in 2011 , and 11.75 in 2012 . There were significant negative correlations between the maternal depression scores and children's ages, and sociability and activity subdomain scores ranged from $\mathrm{r}=-.05$ to $-.11(p<.05)$. There was a significant positive correlation between children's emotionality subdomain scores and maternal depression scores $(\mathrm{r}=.35, p<.001)$. Children's temperament rament (emotionality: $\beta=0.26$, activity: $\beta=-0.07$, and sociability: $\beta=-0.03$ ) were significant factors in maternal depression. Conclusion: These findings indicate the need for the early assessment of and intervention for children's temperament and maternal depression. The results of this study will provide basic data for the development of nursing education programs related to early assessment and intervention to improve the health and quality of life of young children and mothers.
\end{abstract}

Keywords: Child, Preschool, Mothers, Temperament, Depression, Mother-child relations

\section{Introduction}

Depression is highly prevalent disease worldwide and is a major concern for public health. Depression, especially in development crisis situations that transform into mothers, threatens mothers' own health. Maternal depression has been shown to have negative consequences on children's social, emotional, and behavioral development and adaptation, and can contribute to psychological and behavioral disorders in children. In other words, the depression of the mother undergoes a chronic course, which in turn affects the role and function of the mother and may negatively affect the health, development, and family processes of the child over the long term [1-4]. Therefore, it is necessary to pay attention to mother depression, which is a woman who is at higher risk of depression than men and has a significant effect on the development and health of the child [5]. In a meta-analysis of 193 studies that examined the effects of maternal depression on children, results demonstrated that the earlier children were exposed to their mother's depression, particularly if exposure occurred during the first year of life, and if a mother has had a relapse in symptoms, contributed to the development of children's psychopathology [3]. Similarly, following a sample of children over a period of 18 years, Comas, Valentino, and Borkowski [6] reported that children who were exposed to maternal depression

주요어: Child, Preschool, Mothers, Temperament, Depression, Mother-child relations

Address reprint requests to: Choi, Mi-Young

Chungbuk National University, Chungdae-ro 1, Seowon-Gu, Cheongju, Chungbuk, 28644, Republic of Korea

Tel: +82-43-249-1798, Fax: +82-43-266-1710, E-mail: myb98@chungbuk.ac.kr

Received: December 24, 2021 Revised: February 4, 2022 Accepted: February 5, 2022

This is an open access article distributed under the terms of the Creative Commons Attribution Non-Commercial License (http://creativecommons.org/licenses/by-nc/4.0), which permits unrestricted non-commercial use, distribution, and reproduction in any medium, provided the original work is properly cited. 
during early childhood (e.g., at the ages of three and five) had a lower executive function at age 18 than children who were not exposed to maternal depression. In other words, the timing and duration of young children's exposure to maternal depression appear to have negative consequences on children's short-term and long-term development. Therefore, understanding the relationship between maternal depression and related variables and their influence depending on children's age would be beneficial for clinicians and researchers alike. However, the majority of studies have focused on mother's postpartum depression with research on maternal depression occurring after that period being limited [5,7].

Research that has examined factors that affect maternal postpartum depression have explored the variables of maternal age [7], depression during pregnancy [7], history of depression [7], postpartum complications [7], self-efficiency [5], parenting efficacy [7], social support [5], smoking [5], and developmental problems in their children [7]. In recent years, attention has been paid to the influence of children's individual differences, such as temperament or personality $[8,9]$. Temperament can be defined as a personality characteristic that encompasses emotionality, activity level, attention to attention, and self-regulation observed from the beginning of life [9]. Traditionally, the children's temperament is viewed as being like personality but emphasizes biological traits and emotions rather than personality. Research has been conducted to distinguish between temperament and personality, with the consensus being that temperament is like personality in that it is inherent in nature and lasts for a long time. In addition, a child's temperament cannot be categorized based on a single aspect or trait, and these patterned characteristics are present in children in infancy and have been influenced by both genetic and environmental factors and become more stable as the child ages [1]. The categories used to describe temperament have used a variety of labels; however, Buss and Plomin [10] categorized temperament in terms of 1) emotionality, which means the intensity of emotional expression such as crying, anger, fear, and sadness, 2) activity, which means to the level and speed of bodily movements, and 3) sociability, which means to cohesion with others and level of shyness.

This temperament of a child affects the development of the mother-child relationship, depending on how the child's temperament is perceived by the mother. Mothers with postpartum depression were more aware of the difficulty in their infants' temperament than mothers without depression [11], and this is affecting the mother's role to feel difficult [9]. In a study that used data of the Panel Study of Korean Children (PSKC), infant's temperament as assessed by their negative emotions between 11 and 18 months was found to be a factor influencing maternal depression [5]. Thus, children's temperament was identified as being a variable related to maternal depression. Although the mother-child relationship is a dynamic interaction involving their emotions and behaviors, previous studies have primarily focused on the unidirectional negative emotional, behavioral, and developmental consequences of maternal depression of children [3]

The relationship between mother and child is a dynamic reciprocal relationship in which emotions and actions are exchanged with each other. Banard's Child Health Assessment Interaction Theory consists of three concepts: the caregiver, the environment, and the child $[12,13]$. Mother-child interaction can be defined as a reciprocal, goal-directed partnership process that includes both mother-child and dyadic behavioral modalities and includes elements of sensitivity, responsiveness, and stimulation of child development [14]. Thus, further research is needed to examine not only to the effect of a mother's psychological state on her child's development but also the effect of the child's behavior on maternal depression, and the reciprocal relationship of the mother and child. According to the transactional model proposed by Sameroff [15], the relationship between parents and children is described as an advanced exchange that bidirectionally affects each other over time, with the influences interacting in the context of the individual. However, evaluating the influences of this bidirectional causal relationship in cross-sectional design is not possible, and can only be confirmed through longitudinal studies using data from multiple viewpoints to assess transactional influences [16]. In a longitudinal study, Allen et al. [1] found a long-term association between offspring personality and maternal depression. Cross-sectional studies can only identify the effect on transient effects, and have limitations in not clearly explaining the relationship between variables. In particular, it is difficult to find studies on the mutual effect of maternal depression and children's temperament in Korea. Therefore, the purpose of this study is to identify the longitudinal causal relationship between the child's temperament (e.g., emotionality, activity, and sociability) and maternal depression in a sample of mother-child dyads as the children age from two to four years. This study was conducted as secondary data analysis to understand and investigate the associations of children's temperament and maternal depression in Korean mother-child dyads using longitudinal cohort data for the 
third wave (2010), fourth wave (2011), and fifth wave (2012) of the Panel Study of Korean Children (PSKC). This study was conducted to provide basic data for the development of nursing education programs related to early evaluation and intervention to improve the health and quality of life of infants and young children and mothers.

\section{Methods}

\section{Sample}

This study utilized the longitudinal cohort data of PSKC for the third to fifth wave (2010 - 2012) following the regulations on the disclosure and management of primitive data of Korea Institute of Child and Education. The panel study of Korean children is a ten-term, long-term study from 2008 to 2020 , and primary data were collected from 2,078 neonates born in medical institutions in South Korea from April 2008 to July 2008. For the analyses used in the current study, the sample included 1,721 mothers who responded to the survey of all the variables used in this study during the third to fifth wave (2010 to 2012), such as maternal depression, maternal employment, and child's temperament, were selected as the subjects of analysis from the first sample of Korean Children in 2008. The reason for using the data from this period was to confirm the temperament when the age of the primary survey subject reached 2-4 years of age.

\section{Variables}

The variables used in this study were employment status as a maternal characteristic along with temperament, sex, and age as characteristics of the children based on previous research. The maternal depression and related factors were considered with the Panel of Korean Children 3-5th wave (2010-2012) data collection for this study.

Maternal depression

Maternal depression was assessed using the Kessler Depression Scale. This scale was designed by Kessler et al [17]. to measure the mental health of the general population in the U.S. Health Interview Survey. The scale includes six questions that are rated on a five-point scale, with scores ranging from 6 to 30 points. Scores are expressed as $1=n o t$ feeling at all to 5=always feeling, and higher scores indicated higher levels of depressive symptomatology. If the total score was 6-13 points, it was classified as being at a normal level, 14-18 points were classified as having mild/moderate depression, and 19-30 points were classified as severe depression. The reliability of Cronbach's a was .89 in the original study by Kessler et al. [17], .89 in the Korean child panel preliminary study in 2007 , and .91 in the present study.

\section{- Child Temperament}

The EAS (The Emotionality, Activity, and Sociability -Temperament Survey for Children-Parent Ratings) developed by the Panel of Korean Children was used to assess child temperament [18]. The Panel of Korean Children surveyed the EAS in waves 1 to 5 . Sociability was not investigated in the $1 \mathrm{st}$ and 2 nd rounds, and temperament was measured in the $3 \mathrm{rd}$ and 5 th waves with the same instrument including sociability. The EAS scales used in the data of this study were a 5-point Likert scale ranging from $1=$ not at all to 5=agree strongly and consists of a total of 20 items, with total score ranging from 20 to 100 points. The parent-report version of the EAS consists of three subdomains: Emotionality (5 items), Sociability (10 items), and Activity (5 items). In this study, the total score of each subdomain was used. A high score on the Emotionality subdomain means that the child displays a high level of negative emotions, a high score on the Activity subdomain indicates that the child likes to move and has an active and busy character, and a high score on the Sociability subdomain means that the child is outgoing and sociable with other people and less shy.

\section{Ethical Considerations}

This study analyzed secondary data that guaranteed the anonymity and confidentiality of the subjects and was conducted after receiving the approval of IRB (No: CBNU-201808-SBETC -703-01) from the C-University Bioethics Review Committee to which the researcher belongs.

\section{Data Analysis}

The collected data were analyzed using the "nlme" package of $\mathrm{R}$ (version 3.1-137). The demographic characteristics of the mothers and children and the characteristics of the depression -related variables were calculated by the percentage and frequency, the mean, and the standard deviation. The temperament 
and maternal depression of the children by year showed the mean, standard deviation, minimum value, and maximum value. Pearson correlation coefficients among continuous variables such as mother's depression, mother's age, child's age, and child's temperament (emotionality, activity, and sociability) were calculated and used to screen for multivariable analysis. These values are averaged across years.

The segmentation and regression coefficients were estimated using a hierarchical linear model. The data analyzed in this study are Cohort data. Maternal depression, mother's employment status, child's age, and child's temperament (emotionality, activity, and sociability) were collected every year from 2010 to 2012. Since each data was repeated measurement data, it was necessary to estimate random variability between subjects (inter-subject random variability) and random variability within subjects (intra-subject random variability), so a final model was calculated using a hierarchical linear model for repeated measurement data. The intraclass correlation (ICC) of the null hypothesis model was obtained to confirm the need for a hierarchical linear model.

In the hierarchical linear model, mother's job, children' $s$ age and temperament (e.g., sociability, emotionality, and activity) were used with time-varying covariance. In the covariance that did not change with time, the sex of the child was used. The maximum likelihood estimation method and the likelihood ratio test with a significance level of .05 were used to search the optimal model.

\section{Results}

\section{Demographic Characteristics}

Table 1 summarizes the demographic characteristics of the mothers and children. The mean age was 32.80 years (Standard Deviation $[S D]=3.63$ ) with $53.2 \%$ of the mothers being between 30 and 34 years old. Of the mothers, $70.4 \%$ had more than bachelor's degree, and $32.8 \%$ were currently employed. The sex of children was $51.4 \%$ in boys and slightly more than girls.

\section{Outcome Variables}

The mean maternal depression scores were $11.83(S D=4.17)$ in 2010, $11.88(S D=4.52)$ in 2011, and $11.75(S D=4.50)$ in 2012 without significant change. Children's emotionality, activity and sociability scores were not significantly different from year to year. The mean emotionality subdomain scores for children in 2010, 2011, and 2012 were $14.22(S D=3.08), 14.36(S D=3.07)$, and $13.99(S D=3.20)$, respectively. The mean scores each year for the children's activity subdomain were $19.51(S D=2.95), 19.08$ $(S D=3.00)$, and $18.79(S D=3.01)$, and for the children's sociability subdomain were $34.88(S D=5.32), 34.48(S D=5.36)$, and $34.75(S D=5.26)$, respectively (Table 2$)$.

\section{Correlations Between Variables}

There were significant negative correlations between the maternal depression score and children's age, and sociability and activity subdomain scores ranging from $r=-.05$ to -.11 . However,

Table 1. Demographics and General Characteristics in the First Year, 2010

$(\mathrm{N}=1,721)$

\begin{tabular}{|c|c|c|}
\hline Characteristics & Categories & n (\%) \\
\hline \multirow[t]{6}{*}{ Mother's age } & $<25$ & $24(1.4)$ \\
\hline & $25-29$ & $261(15.2)$ \\
\hline & $30-34$ & $916(53.2)$ \\
\hline & $35-39$ & $456(26.5)$ \\
\hline & $\geq 40$ & $64(3.7)$ \\
\hline & Mean \pm SD & $32.80 \pm 3.63$ \\
\hline \multirow[t]{3}{*}{ Mother's education ${ }^{*}$} & High school or less & 477 (29.6) \\
\hline & College & $403(25.0)$ \\
\hline & University or more & $733(45.4)$ \\
\hline \multirow[t]{2}{*}{ Mother's job } & Yes & $564(32.8)$ \\
\hline & No & $1,157(67.2)$ \\
\hline \multirow[t]{2}{*}{ Child's sex } & Boy & $884(51.4)$ \\
\hline & Girl & $837(48.6)$ \\
\hline
\end{tabular}

${ }^{*}$ No response is excluded 
there was not significant negative correlations between the maternal depression score and mother's age $(r=-.02, p=.469)$. There was a significant positive correlation between children's emotionality subdomain scores and maternal depression scores (Table 3).

\section{Factors Influencing Maternal Depression}

To identify the factors affecting maternal depression as the child's age increases, a hierarchical regression model of mother's depression is calculated by using mother's job, child's age, sex and sociability, emotionality, and activity temperament, respectively. The ICC (Intraclass Correlation) of the null hypothesis model was $.53(p<.001)$, which justifies using a hierarchical model.

The final hierarchical regression model is as follows.

$$
\begin{aligned}
& E\left(y_{i j}\right)=\beta_{0}+\beta_{1}\left(M_{t} J o b_{i j}\right)+\beta_{2}\left(\operatorname{ChSex}_{i}\right)+\beta_{3}\left(\text { hAge }_{i j}\right)+\beta_{4}\left(\operatorname{ChSoc}_{i j}\right)+ \\
& \beta_{5}\left(C h E m t_{i j}\right)+\beta_{6}\left(C h A c t_{i j}\right) y_{i j} \\
& \mathrm{y}_{\mathrm{ij}}=E\left(y_{i j}\right)+u_{i}+E\left(y_{i j}\right)^{\ominus} \mathcal{E}_{i j}
\end{aligned}
$$

MtJob : Mother Job $\{0=$ None or student $1=$ Having job
ChSex : Child Sex $\{0=$ female $1=$ male
ChAge : Child Age in months
ChSoc : Child Social Score
ChEmt : Child Emotion
ChAct $:$ Child Activity
E(yij): Expectation of $y_{i j}$
$u_{i} \sim N\left(0, \sigma_{1}^{2}\right)$
$\mathcal{E}_{i j} \sim N\left(0, \sigma_{2}^{2}\right)$

Children's scores on the emotionality, activity, and sociability subdomains of the EAS were significant factors for predicting maternal depression scores. As children's negative emotions increased, their mother's depressive score increased, and as children's activity level increased, mother's depressive score decreased (Table 4). The standard deviation of the inter-subject variability was estimated to be 2.73 , and the standard deviation of the intra-subject variability was 0.08 . A power error model was used, and the exponent $(\Theta)$ was estimated as 1.50 .

\section{Discussion}

The purpose of this study was to examine the patterns of childhood temperament and maternal depression in a sample of 1,721 mothers and their children who participated in the third, fourth and fifth year of the PSKC. In addition, in order to investigate the effect of children's temperament of the mother on the depression of the mother, we used longitudinal data and a hierarchical linear model to identify causal relationships over time, which are novel aspects of the current study.

Our results demonstrated several key findings. First, the three temperament subdomains (i.e., emotionality, activity, sociality) and maternal depression scores were all relatively stable over time. These results are consistent with previous studies that have reported the temporal stability of parent-reported child's temperament [19] and maternal depression [20-23] and suggestions that children's temperament and maternal depression and they are affected by previous temperament traits or depressive symptoms, rather than being temporary attributes. The lack of

\begin{tabular}{|c|c|c|c|c|}
\hline Variables & Year & Mean \pm SD & Min & Max \\
\hline Maternal depression & 2010 & $11.83 \pm 4.17$ & 6 & 29 \\
\hline \multirow[t]{2}{*}{ (Range 6 630 ) } & 2011 & $11.88 \pm 4.52$ & 6 & 30 \\
\hline & 2012 & $11.75 \pm 4.50$ & 6 & 30 \\
\hline \multirow{3}{*}{$\begin{array}{l}\text { Child's temperament: Emotionality } \\
\text { (Range 5 25) }\end{array}$} & 2010 & $14.22 \pm 3.08$ & 6 & 25 \\
\hline & 2011 & $14.36 \pm 3.07$ & 5 & 25 \\
\hline & 2012 & $13.99 \pm 3.20$ & 5 & 25 \\
\hline \multirow{3}{*}{$\begin{array}{l}\text { Child's temperament: Activity } \\
\text { (Range 5 25) }\end{array}$} & 2010 & $19.51 \pm 2.95$ & 7 & 25 \\
\hline & 2011 & $19.08 \pm 3.00$ & 9 & 25 \\
\hline & 2012 & $18.79 \pm 3.01$ & 8 & 25 \\
\hline \multirow{3}{*}{$\begin{array}{l}\text { Child's temperament: Sociability } \\
\text { (Range } 10 \sim 50 \text { ) }\end{array}$} & 2010 & $34.88 \pm 5.32$ & 11 & 49 \\
\hline & 2011 & $34.48 \pm 5.36$ & 14 & 49 \\
\hline & 2012 & $34.75 \pm 5.26$ & 12 & 50 \\
\hline
\end{tabular}

Table 2. Means, Standard Deviations for Studied Variables

$(\mathrm{N}=1,721)$ 
awareness of the influence of children's temperament on the long-term patterns of maternal depression suggests the importance of early intervention shortly after the birth of the child, as this relationship can have negative consequences for children and mothers [24]. Given the results of this study, early evaluation and intervention are needed to identify and treat maternal depression, considering the temperament of young children.

Studies have also reported that temperament persists similarly to personality. But children's temperament is malleable in infancy and early childhood, and reactivity to control and response inhibition do not appear until late infancy [25]. Thus, temperament can be modified and influenced by the child's interaction of the environment and experience $[25,26]$. Since the positive aspects of children's temperament (e.g., low emotionality, high sociability) may contribute to decreases in maternal depressive symptoms experienced during early childhood, and the relationship between maternal depression is known to contribute to subsequent behavioral and cognitive traits in children, a system should be established to identify and address temperament characteristics before the start of children's formal education [6]. Temperament-based education and parenting programs to help build positive parenting skills to help mothers develop a better understanding of their children are needed. Such programs should focus on increasing maternal awareness of children's innate

Table 3. Correlations among Studies Variables

$(\mathrm{N}=1,721)$

\begin{tabular}{|c|c|c|c|c|c|c|}
\hline Variables & $\begin{array}{c}1 \\
r(p) \\
\end{array}$ & $\begin{array}{c}2 \\
r(p) \\
\end{array}$ & $\begin{array}{l}3 \\
r(p) \\
\end{array}$ & $\begin{array}{c}4 \\
r(p) \\
\end{array}$ & $\begin{array}{l}5 \\
r(p)\end{array}$ & $\begin{array}{l}6 \\
r(p) \\
\end{array}$ \\
\hline 1. Maternal depression & 1.00 & & & & & \\
\hline 2. Child's age & $\begin{array}{c}-.05 \\
(.017)\end{array}$ & 1.00 & & & & \\
\hline 3. Child's temperament: Emotionality & $\begin{array}{c}.35 \\
(<.001)\end{array}$ & $\begin{array}{c}-.00 \\
(.856)\end{array}$ & 1.00 & & & \\
\hline 4. Child's temperament: Activity & $\begin{array}{c}-.07 \\
(.001)\end{array}$ & $\begin{array}{c}-.08 \\
(<.001)\end{array}$ & $\begin{array}{c}-.05 \\
(.028)\end{array}$ & 1.00 & & \\
\hline 5. Child's temperament: Sociability & $\begin{array}{c}-.11 \\
(<.001)\end{array}$ & $\begin{array}{c}.00 \\
(.960)\end{array}$ & $\begin{array}{c}-.19 \\
(<.001)\end{array}$ & $\begin{array}{c}.58 \\
(<.001)\end{array}$ & 1.00 & \\
\hline 6. Mother's age & $\begin{array}{c}-.02 \\
(.469)\end{array}$ & $\begin{array}{c}.06 \\
(.005)\end{array}$ & $\begin{array}{c}-.07 \\
(.001)\end{array}$ & $\begin{array}{c}-.12 \\
(<.001)\end{array}$ & $\begin{array}{c}-.05 \\
(.023)\end{array}$ & 1.00 \\
\hline
\end{tabular}

Table 4. Hierarchical Linear Model of Mother's Depression over time

\begin{tabular}{|c|c|c|c|c|c|c|}
\hline \multicolumn{7}{|l|}{ (a) Fixed effect } \\
\hline Parameter & Categori & ries & Estimate & Standard error & $\mathrm{t}$-value & p-value \\
\hline Intercept $\beta_{0}$ & & & 10.17 & 0.54 & 18.82 & $<.001$ \\
\hline \multirow[t]{2}{*}{ Mother's Job $\beta_{1}$} & No & & 0 & & & \\
\hline & Yes & & -0.16 & 0.12 & -1.38 & .166 \\
\hline \multirow[t]{2}{*}{ Child's Sex $\beta_{2}$} & Girl & & 0 & & & \\
\hline & Boy & & 0.13 & 0.15 & 0.87 & .380 \\
\hline Child's Age $\beta_{3}$ & & & -0.01 & 0.00 & -1.53 & .125 \\
\hline Child's Temperament: Sociability $\beta_{4}$ & & & -0.03 & 0.01 & -2.51 & .012 \\
\hline Child's Temperament: Emotionality $\beta_{5}$ & & & 0.26 & 0.02 & 15.06 & $<.001$ \\
\hline Child's Temperament: Activity $\beta_{6}$ & & & -0.07 & 0.02 & -3.65 & $<.001$ \\
\hline \multicolumn{7}{|l|}{ (b) Random effect } \\
\hline \multirow[t]{3}{*}{ Parameter } & \multicolumn{3}{|c|}{ 95\% Lower bound } & Estimate & \multicolumn{2}{|c|}{ 95\% Upper bound } \\
\hline & \multicolumn{3}{|c|}{2.59} & 2.73 & \multicolumn{2}{|r|}{2.87} \\
\hline & \multicolumn{3}{|c|}{0.06} & 0.08 & \multicolumn{2}{|r|}{0.11} \\
\hline \multicolumn{7}{|l|}{ (c) Residual error: Power model } \\
\hline \multirow[t]{2}{*}{ Parameter } & \multicolumn{3}{|c|}{ 95\% Lower bound } & Estimate & \multicolumn{2}{|c|}{ 95\% Upper bound } \\
\hline & \multicolumn{3}{|c|}{1.37} & 1.50 & \multicolumn{2}{|r|}{1.64} \\
\hline
\end{tabular}


temperament characteristics and understanding its role in the development of young children and the parent-child relationship [27].

Second, children's temperament (emotionality, activity, sociability) was found to have a statistically significant effect on maternal depression. In other words, as children have more negative emotionality, the less likely they are to have high levels of activity and sociability, which then, in turn, increases the depression in mothers. These results support the transactional model of parent-child relationships proposed by Sameroff [15], suggesting that the temperament of the child and the depression of the mother are bidirectionally influencing each other over time. This suggests that children's temperament and maternal depression are organically related. To fully understand the relationship between children's temperament and maternal depression, researchers need to consider not only how the children' $\mathrm{s}$ temperament is influenced by maternal depression but also the concurrent and subsequent effects of child temperament on maternal depression.

Although there are few studies that we can directly compare with the current results given the age range of children and the methods of assessing temperament, one study [21] that examined negative emotionality in one-year-old children showed results that were similar to the current findings and also reported that mother's depression at age two then affected mother's parenting behavior when their children were three years old. Parents with children who have challenging temperament including a high level of negative emotionality are at increased likelihood for experiencing significant depression while parenting [28], which supports the current findings that indicate that there are bidirectional influences between child temperament and parents' negative parenting behavior [19]. In addition, research [9] has shown that there is a positive relationship between prenatal depressive symptomatology and postnatal depression such that high levels of postpartum depressive symptomatology are positively associated with difficult infant temperament, which is consistent with the current results. Therefore, it may be necessary to provide specialized support to mothers of children with difficult temperaments to help them establish what they need to do when the child is overly emotional and hard to sooth and to help them establish good dietary habits [8]. Therapeutic interventions for these mothers and children should include ways to positively manage maternal depression and mothers' emotions, as well as education regarding behavior management skills to cope with children's crying, diet, and sleep. These interventions should also support the development of mother-child synchrony, in which depressed mothers develop their parenting role as a mother and focus on increasing their harmony and attunement with the child's temperament [24]. If a mother can have intimacy with her child, even when depressive symptoms persist, she is better able to adapt to her role as a mother. Therefore, mothers of children with challenging temperaments need intervention programs that include elements such as education to increase their responsiveness to their children and encourage mother-child intimacy [24]. Further research is needed to focus on developing interventions that reduce parental stress and increase parents' coping resources when children have high negative emotionality, low activity, and low sociability [6].

Using a longitudinal design, we found further support for the need for interventions focused on improving early relationships and environments for depressed mothers' children. In a study by Yan and Dix [23], maternal depression and mother-child mutual responsiveness in early childhood were found to be interdependent with time. Thus, the sensitivity or reactivity of a mother when directly responding to an infant's signal may help the child adjust her attention and emotions, as depressed mothers are at increased risk for the lack of sensitivity to the needs and signals of infants, have difficulty in responding appropriately to their children, and experience more stress related to parenting [29]. Establishing and implementing concrete measures to increase maternal sensitivity or responsiveness that encourages positive relationship experiences with their children in early childhood is needed [30,31]. In addition, as primary caregivers need to develop healthy and appropriate parenting skills to promote children's optimal development, especially neurocognitive development, it is important to ensure that primary caregivers do not mistreat or abuse the child [6].

The results of this study showed that children's temperament and mother's depression had an influence on each other. However, in Hanington et al [32]'s study which confirmed the relationship between parental depression and children's temperament at 2 time points when children reached 6 and 24 months of age, there was reported little evidence for the effect of child temperament on parental depression. To confirm the validity of this study, it is necessary to further study the influence of the children's temperament characteristics in early childhood on maternal depressive symptoms using longitudinal data. In addition, since there is a possibility that the type and size of mutual influence 
between mother and child may change with the ongoing development of children, longitudinal designs that allow for repeated data collection should be used to clearly understand the mutual influence of children's temperament and maternal depression from infancy to adolescence.

This study is meaningful in that it longitudinally evaluated the effects of children's temperament on maternal depression using three waves of panel date; however, the study had several limitations. First, in this study, children's temperament and maternal depression were both measured using the mother's report. Therefore, it is possible that the relationship between the variables was overestimated or underestimated according to the perceptions of the mother. Thus, in subsequent studies, it would be beneficial to explore the relationship between variables by using objective data collecting using observations or reports by a third party, such as a teacher. Second, since the analysis was not conducted using data from mothers who were diagnosed with major depression or clearly indicated the period of depression, caution is needed in interpreting the results of this study. Third, this study confirmed the association between the study variables by considering the temporal precedence using a hierarchical linear model, but it is difficult to grasp the individual internal changes over time. Therefore, it is necessary to examine the characteristics of the child's temperament and the trajectories of change in maternal depression using growth models.

\section{Conclusions and Recommendations}

This study used a hierarchical linear model to identify the temporal and bidirectional relationship between children's temperament and mothers' depressive symptoms. The current results showed that there was an association between maternal depression and the child's temperament during young childhood. The results of this study showed that the temperament characteristics of the child and the depression of the mother are crucial to mother-child interactions and suggest that early assessment and intervention of children's temperament and maternal depression are necessary.

\section{Conflict of interest}

No potential conflict of interest relevant to this article was reported.

\section{Funding}

None

\section{Acknowledgements}

None

Supplementary materials

None

\section{References}

1. Allen TA, Oshri A, Rogosch FA, Toth SL, Cicchetti D. Offspring personality mediates the association between maternal depression and childhood psychopathology. Journal of Abnormal Child Psychology. 2019;47(2):345-357. https://doi.org/ 10.1007/s10802-018-0453-3

2. Gaillard A, Le Strat Y, Mandelbrot L, Keïta H, Dubertret C. Predictors of postpartum depression: Prospective study of 264 women followed during pregnancy and postpartum. Psychiatry Research. 2014;215(2):341-346. https://doi.org/10. 1016/j.psychres. 2013.10.003

3. Goodman SH, Rouse MH, Connell AM, Broth MR, Hall CM, Heyward D. Maternal depression and child psychopathology: A meta-analytic review. Clinical Child and Family Psychology Review. 2011;14(1):1-27. https://doi.org/10.1007/s10567-010 $-0080-1$

4. Letourneau NL, Tramonte L, Willms JD. Maternal depression, family functioning and children's longitudinal development. Journal of Pediatric Nursing. 2013;28(3):223-234. https://doi.org/ 10.1016/j.pedn.2012.07.014

5. Kim C-G, Choi M-Y. Factors influencing maternal depression: Secondary data analysis. Korean Journal of Adult Nursing. 2016;28(3):288-301. https://doi.org/10.7475/kjan.2016.28.3.288

6. Comas M, Valentino K, Borkowski JG. Maternal depressive symptoms and child temperament: Longitudinal associations with executive functioning. Journal of Applied Developmental Psychology. 2014;35(3):156-167. https://doi.org/10.1016/j.appdev. 2014.03.005

7. Giallo R, Cooklin A, Wade C, D'Esposito F, Nicholson J. Maternal postnatal mental health and later emotionalbehavioural development of children: The mediating role of 
parenting behaviour. Child: care, health and development. 2014;40(3):327-336. https://doi.org/10.1111/cch.12028

8. Martini J, Petzoldt J, Knappe S, Garthus-Niegel S, Asselmann E, Wittchen H-U. Infant, maternal, and familial predictors and correlates of regulatory problems in early infancy: The differential role of infant temperament and maternal anxiety and depression. Early Human Development. 2017;115:23-31. https://doi.org/10.1016/j.earlhumdev.2017.08.005

9. Rode JL, Kiel EJ. The mediated effects of maternal depression and infant temperament on maternal role. Archives of Women's Mental Health. 2016;19(1):133-140. https://doi.org/ 10.1007/s00737-015-0540-1

10. Buss A, Plomin R. The EAS approach to temperament. The Study of Temperament. Hillsdale, NJ: Erlbaum; 1986. p. 67-79.

11. Bang K-S. Infants' temperament and health problems according to maternal postpartum depression. Journal of Korean Academy of Nursing. 2011;41(4):444-450. https://doi.org/ 10.4040/jkan.2011.41.4.444

12. Barnard $\mathrm{K}$. The nursing child assessment satellite training (NCAST) Teaching Scale. Seattle, WA: NCAST Programs. 1994.

13. Alligood M, Tomey A. Nursing theorists and their work 7th ed., 2010. Maryland: Mosby Elsevier. p. 61-63

14. Park S-H, Bang K-S. Concept analysis of mother-child interaction. Child Health Nursing Research. 2011;17(2): 120-126. https://doi.org/10.4094/jkachn.2011.17.2.120

15. Sameroff AJ. Conceptual issues in studying the development of self-regulation. Biopsychosocial Regulatory Processes in the Development of Childhood Behavioral Problems. 2009:1-18.

16. Sameroff AJ, Mackenzie MJ. Research strategies for capturing transactional models of development: The limits of the possible. Development and Psychopathology. 2003;15(3): 613-640. https://doi.org/10.1017/s0954579403000312

17. Kessler RC, Andrews G, Colpe LJ, Hiripi E, Mroczek DK, Normand S-L, et al. Short screening scales to monitor population prevalences and trends in non-specific psychological distress. Psychological Medicine. 2002;32(6):959-976. https://doi.org/10.1017/S0033291702006074

18. Korea Institute of Child Care and Education (KICCE). Panel study on Korean children tool profile [Internet]. Seoul: KICCE; c2008 [cited 2020 Mar 4]. Available from: https://panel. kicce.re.kr/pskc/board/view.do?menu_idx=42\&board_idx $=333$ $60 \&$ manage_idx $=26 \&$ old_menu_idx $=0 \&$ old_manage_idx $=0 \& 0$ ld_board_idx $=0 \&$ group_depth $=0 \&$ parent_idx $=0 \&$ group_idx $=0$ \&group_ord $=0 \&$ viewMode $=$ NORMAL\&search_type $=$ title\&sea rch_text=\%EA $\%$ B8\%B0\%EC\%A7\%88\&rowCount=10\&viewP age $=1$

19. Micalizzi L, Wang M, Saudino KJ. Difficult temperament and negative parenting in early childhood: A genetically informed cross-lagged analysis. Developmental Science. 2017;20(2): e12355. https://doi.org/10.1111/desc.12355

20. Chang YE, Han HJ. A short-term longitudinal study on the reciprocal relations between mothers' depression and their preschoolers' emotional problems. Family and Environment Research. 2016;54(5):551-564. https://doi.org/10.6115/fer.2016. 043

21. Kim AH, Doh HS. Transactional relationships among children's negative emotionality, mothers' depression, and parenting behavior. Korean Journal of Child Studies. 2018; 39(3):45-59. https://doi.org/10.5723/kjcs.2018.39.3.45

22. Mathis ET. Maternal depression, negative parenting practices, and child oppositional-aggression: Bidirectional influences over time [dissertation]. Pennsylvania : The Pennsylvania State University; 2016. p. 1-79.

23. Yan N, Dix T. Mothers' early depressive symptoms and children's first-grade adjustment: A transactional analysis of child withdrawal as a mediator. Journal of Child Psychology and Psychiatry. 2014;55(5):495-504. https://doi.org/10.1111/ jcpp. 12189

24. McGrath JM, Records K, Rice M. Maternal depression and infant temperament characteristics. Infant Behavior and Development. 2008;31(1):71-80. https://doi.org/10.1016/j.infbeh. 2007.07.001

25. Shiner RL, Buss KA, McClowry SG, Putnam SP, Saudino KJ, Zentner M. What is temperament now? Assessing progress in temperament research on the Twenty-Fifth Anniversary of Goldsmith et al. Child Development Perspectives. 2012;6(4):436-444.

26. Rothbart MK, Posner MI, Kieras J. Temperament, attention, and the development of self-regulation. In K. McCartney \& D. Phillips, editors. Blackwell handbook of early childhood development. 1st ed. New Jersey: Blackwell Publishing; 2006. p. 338-357.

27. Ahn MS. Effects of a maternal education program based on the temperament theory on the temperamental goodness-of-fit between mother and child. Journal of Korean Academy of Nursing. 2005;35(6):1044-1053. https://doi.org/10.4040/jkan. 
2005.35.6.1044

28. Britton JR. Infant temperament and maternal anxiety and depressed mood in the early postpartum period. Women \& Health. 2011;51(1):55-71. https://doi.org/10.1080/03630242. 2011.540741

29. Turney K. Chronic and proximate depression among mothers: Implications for child well-being. Journal of Marriage and Family. 2011;73(1):149-1063. https://doi.org/10.1111/j.17413737.2010.00795.x

30. Frick MA, Forslund T, Fransson M, Johansson M, Bohlin G, Brocki KC. The role of sustained attention, maternal sensitivity, and infant temperament in the development of early self- regulation. British Journal of Psychology. 2018;109(2): 277-298. https://doi.org/10.1111/bjop.12266

31. Rispoli KM, McGoey KE, Koziol NA, Schreiber JB. The relation of parenting, child temperament, and attachment security in early childhood to social competence at school entry. Journal of School Psychology. 2013;51(5):643-658. https://doi.org/10.1016/j.jsp.2013.05.007

32. Hanington L, Ramchandani P, Stein A. Parental depression and child temperament: Assessing child to parent effects in a longitudinal population study. Infant Behavior and Development. 2010;33(1):88-95. https://doi.org/10.1016/j.infbeh. 2009.11.004 